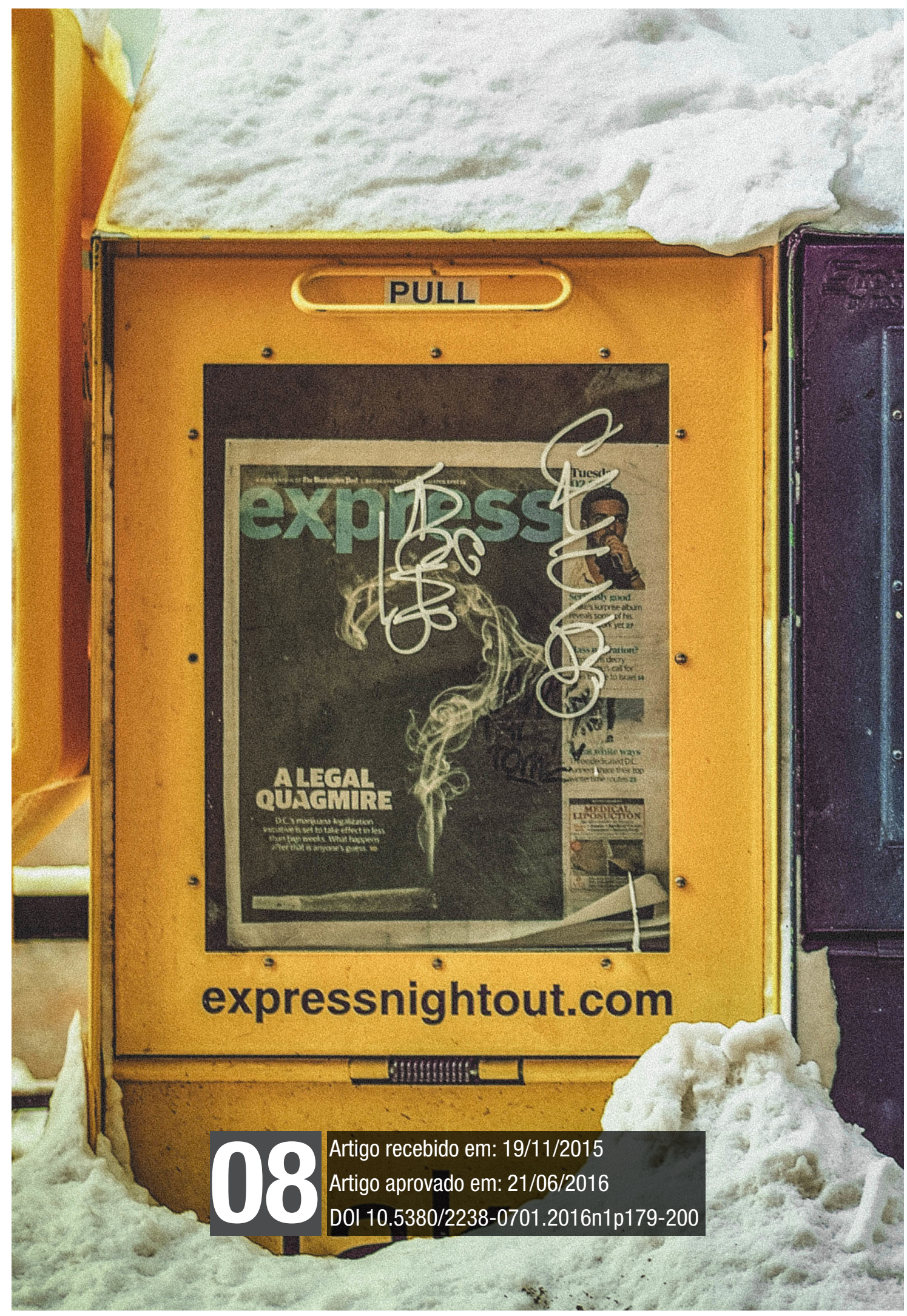


Cultura da convergência. Câmara dos Deputados.

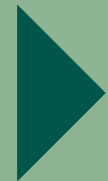




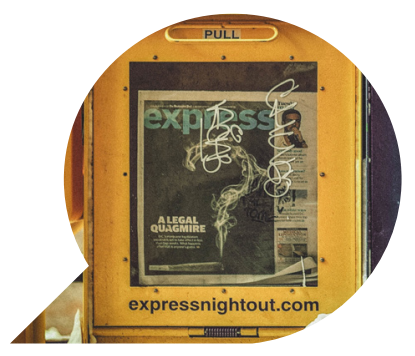

\title{
A cultura da convergência e as práticas discursivas em publicações oficiais da Câmara dos Deputados do Brasil: um estudo multimodal diacrônico
}

\author{
The culture of convergence and discursive practices in \\ official publications of the Chamber of Deputies of Brazil: a \\ diachronic multimodal study
}

La cultura de la convergencia y las prácticas discursivas en las publicaciones oficiales de la Cámara de los Deputados de Brasil: un estudio diacrónico multimodal

\begin{tabular}{c}
\hline JANAÍNA DE AQUINO FERRAZ * $^{*}$ \\
\hline ROSANE QUEIROZ GALVÃO $^{* *}$ \\
\hline
\end{tabular}

\footnotetext{
${ }^{*}$ Doutora em Linguística, pelo PPGL da Universidade de Brasília; Membro da Associação Brasileira de Linguística - ABRALIN, do Grupo de Estudos de Linguística do Centro Oeste - GELCO e da Associação Latinoamericana de Estudos do Discurso - ALED. Diretora do Centro Interdisciplinar de Formação Continuada (INTERFOCO) do Decanato de Extensão da Universidade de Brasília e Professora da Licenciatura em Letras Português do Brasil como Segunda Língua do Departamento de Linguística, Português e Línguas Clássicas - LIP da UnB. E-mail: ferraz.jana@gmail.com

${ }^{* *}$ Mestra em Linguística, pelo Programa de Pós-Graduação em Linguística - PPGL, da Universidade de Brasília (UnB); possui especialização em Português Jurídico pela Universidade Cândido Mendes (2011) e especialização em Língua Portuguesa pelo Centro Universitário de Brasília (2006); atua profissionalmente como Analista Legislativa da Câmara dos Deputados, onde exerce a função de Revisora de Pronunciamentos; graduada em Direito pelo Centro Universitário de Brasília (1994), com especialização em Direito Civil. E-mail: rosane.galvao@camara.leg.br
} 
Resumo: Esse estudo apresenta uma reflexão acerca do fenômeno chamado cultura da convergência e seus efeitos sobre a linguagem empregada em capas de jornais impressos da Câmara dos Deputados do Brasil, como marca de mudança na paisagem semiótica da comunicação social institucional. Buscamos, em primeiro lugar, a compreensão do conceito de cultura da convergência. Em seguida, apresentamos os efeitos concretos do fenômeno nas estruturas dos órgãos de comunicação social da Câmara dos Deputados do Brasil e em suas práticas discursivas. Num terceiro momento, ajustamos o foco à evolução da linguagem multimodal de um dos veículos de comunicação impressos da Câmara dos Deputados, o Jornal da Câmara. Por fim, esteados nos preceitos da Análise Crítica de Discurso e na Teoria Semiótica Social da Multimodalidade, intentamos revelar como as mudanças discursivas coadunam-se às novéis práticas sociais ligadas à chamada cultura da convergência.

Palavras-Chave: Cultura da convergência; Discurso político; Mídia; Multimodalidade.

Abstract: The study presents a reflection on the phenomenon called the convergence culture and its effects on the language used on the newspapers of the Chamber of Deputies of Brazil, as rebranding the semiotic landscape institucional media. We search in the first place the understanding and concept of the convergence culture. We then present the actual effects of the phenomenon in the media structures of the Chamber of Deputies of Brazil and in their discursive practices. Thirdly, we adjust the focus to the development of multimodal language of one of the media of the House of Representatives, through the collation of two editions of the Journal of the House. Finally, based on the precepts of Discourse Analysis and Critical Social Theory of Semiotics Multimodality, intend to reveal how the discursive changes fit well to contemporary social practices related to the so-called culture of convergence.

Key Words: Convergence culture; Media; Political discourse; Multimodality. 
Resumen: En este estudio es presentado una reflexión sobre el fenómeno llamado cultura de la convergencia y sus efectos sobre el lenguaje usado em periódicos de la Cámara de los Deputados de Brasil. En primer lugar buscamos compreender el concepto de cultura de convergencia. En segundo lugar presentamos los efectos concretos del fenómeno en las estructuras de los órganos de comunicación social de la Cámara de los Deputados de Brasil y sus prácticas discursivas. En un tercer momento ajustamos el foco para la evolución del lenguaje multimodal de uno de los vehículos de comunicación impresos en la Cámara de los Deputados, con base en los preceptos del Análisis Crítico del Discurso así como en la Teoría Semiótica Social de la Multimodalidad.

Palabras clave: Cultura de la convergencia; Media; Discurso político; Multimodalidad. 


\section{Introdução}

Este estudo busca proceder à análise discursiva crítica e semiótica de textos impressos em capas do jornal produzido pela mídia institucional da Câmara dos Deputados considerando o novel fenômeno chamado cultura da convergência. Evidenciam-se, portanto, sinais de mudanças na produção de textos multimodais que carregam, a um só tempo, atributos inerentes a gêneros distintos: trata-se de discurso institucional público, político e midiático.

Nesta reflexão acerca do fenômeno cultura da convergência e de seus vestígios sobre a linguagem empregada nas edições impressas do Jornal da Câmara, percorremos três passos: primeiramente, buscamos compreender o fenômeno da cultura da convergência examinando os conceitos que se lhe apresentam. Em seguida, apresentamos alguns efeitos já concretos do fenômeno nas estruturas dos órgãos de comunicação social da Câmara dos Deputados e em suas práticas discursivas. E, finalmente, ajustamos o foco à análise da linguagem e dos recursos semióticos empregados na produção das capas do Jornal da Câmara.

Nesta última tarefa, com base nas categorias de análise da Gramática do Design Visual (KRESS; VAN LEEUWEN, 2006), procedemos ao cotejo das capas de seis edições do Jornal da Câmara, desde o final da década de 90. Vale salientar que, no final dessa década, passam a fazer parte do sistema de comunicação da Câmara dos Deputados a TV Câmara e a Rádio Câmara, e a página virtual começou a ser veiculada a partir do ano 2000. Nessa medida, justifica-se a escolha do corpus pelo intento de vislumbrar a evolução da linguagem do jornal oficial impresso a partir do momento em que surgem outras mídias, as quais, anos mais tarde, integraram-se, já como fruto do fenômeno da convergência na Casa de Leis. Inicia-se a análise a partir de um tempo em que ainda parecia central o modo escrito (logocentrismo) na linguagem do jornal impresso institucional até o momento atual, quando parece haver tendência ao emprego de recursos semióticos multimodais, especialmente os imagéticos.

De nosso aporte teórico, para revelar como as mudanças discursivas coadunam-se às novéis (e ainda em construção) práticas ligadas à cultura da convergência, o estudo esteia-se nos preceitos da Análise Crítica de Discurso (ADC) propostos por Fairclough $(2001,2003)$ e 
nas bases da Teoria Semiótica Social da Multimodalidade, capitaneada por Gunther Kress e Theo van Leeuwen (2001). Da ADC emprestamos o método (análise da prática social à prática discursiva e textual) e o pressuposto de que "a linguagem (e mais amplamente 'semioses', incluindo, por exemplo, significação e comunicação por meio de imagens visuais) é um elemento do social em todos os níveis" (FAIRCLOUGH, 2003), e de que há relações de poder e ideologias envolvidas com a linguagem, estando a prática discursiva presente em todos os processos de mudança cultural e social (FAIRCLOUGH, 2001, p. 292).

Da Teoria Semiótica Social da Multimodalidade (KRESS; VAN LEEUWEN, 2006), tomamos o conceito de multimodalidade como o uso de diversos modos semióticos na construção de um produto ou evento semiótico, junto com uma forma particular como esses modos se combinam. $\mathrm{Na}$ análise do objeto empírico, capas de edições impressas do Jornal da Câmara, aplicam-se categorias de análise propostas pela Gramática do Design Visual (KRESS; VAN LEEUWEN, 2006) relativas à composição espacial do significado, como valor da informação, saliência e moldura, além da projeção, que leva em conta a composição e a integração de códigos, e trajetória de leitura. Dos objetivos propostos advêm os nossos questionamentos:

1. O que significa cultura da convergência como nova prática social?

2. Que efeitos concretos a dita cultura da convergência provoca nas práticas discursivas da comunicação parlamentar da instituição Câmara dos Deputados?

3. Como a linguagem da mídia impressa (Jornal da Câmara) da Câmara dos Deputados é afetada pela cultura da convergência, como prática textual?

\section{A cultura da convergência como prática social contemporânea}

A Câmara dos Deputados do Brasil, órgão do Poder Legislativo da República Federativa brasileira, incorpora a democracia representativa e, por meio de seus órgãos de comunicação, busca a proximidade com o cidadão que representa a opinião pública, construída na chamada esfera pública (HABERMAS, 1984). Mas, como alertam as palavras do então Deputado Tancredo Neves, proferidas no Congres- 
so Nacional, na sessão do dia 18 de setembro de 1951, “a democracia é [...] um ideal em permanente dinamismo, que se transforma e aperfeiçoa num incessante desenvolvimento que não lhe permite conquistas pacíficas e definitivas”. [...] (BRASIL, 1951, p. 8.273-8.274).

Esse esforço permanente pela mantença das instituições e seus ideais democráticos se recrudesce na era da cibercultura, mas, embora protagonizem a comunicação social, as mídias ditas virtuais ainda testemunham a resistência e sobrevida das mídias impressas, e ambas continuam relevantes para a legitimidade buscada pelos sistemas políticos, conforme corrobora a análise sociológica de Manuel Castells:

os sistemas políticos estão mergulhados em uma crise estrutural de legitimidade, periodicamente arrasados por escândalos, com dependência total da cobertura da mídia e de liderança personalizada, e cada vez mais isolados dos cidadãos. [...] (CASTELLS, 1999, p. 41).

É de elevado valor, portanto, o papel dos órgãos de comunicação social da Câmara dos Deputados no esteio da condição democrática brasileira e no fortalecimento do Parlamento nacional, especialmente em ambiente de crise estrutural de legitimidade. As metas e estratégias que estabelecem para si demonstram a grandeza da tarefa de

contribuir para o desenvolvimento da cidadania; contribuir para o fortalecimento institucional da Câmara; e ser referência em comunicação pública [..] [por sua vez, gerando estratégias para] gerar informações em linguagem adequada, de forma isenta, apartidária e confiável; intensificar a comunicação dos trabalhos e resultados positivos da Câmara, sem prejuízo da cobertura jornalística; e ampliar e aperfeiçoar canais de distribuição e de interatividade. [...] (BRASIL, 2013, p. 23).

Ao enfoque analítico semiolinguístico deste estudo, parece-nos relevante a estratégia de "gerar informações em linguagem adequada”. Mas adequar-se a quem e a quê? Com efeito, tal adequação implica considerar os participantes interativos das comunicações públicas e as novas práticas sociais e discursivas advindas da integração das mídias e das tecnologias de comunicação - as antigas, em reconfiguração, e as novas - que as possibilitam e suportam. Logo, "a noção de convergência parte do princípio de que as diferentes mídias tendem a ser agregadas e ressignificadas na experiência dos indivíduos, gerando novas articulações na maneira como esses fenômenos são 
vivenciados". [...] (MARTINO, 2014. p. 36).

Assim, toda a complexa tarefa da Secretaria de Comunicação Social (Secom) da Câmara dos Deputados consubstancia-se na inescapável convergência das mídias, fenômeno cujos efeitos - alguns, entre muitos - investigamos neste artigo, com enfoque nas alterações da linguagem empregada em certa mídia antiga, milenar: os jornais impressos.

Vê-se a expressão "cultura da convergência” presente em estudos de comunicação e mídias digitais, porém, o fenômeno atinge tanto as novas quanto as antigas mídias. Henry Jenkins, em sua obra Convergence Culture: Where Old and New Media Collide, defende que

se o paradigma da revolução digital presumia que as novas mídias substituiriam as antigas, o emergente paradigma da convergência presume que novas e antigas mídias irão interagir de formas cada vez mais complexas. [...] Cada vez mais, líderes da indústria midiática estão retornando à convergência como uma forma de encontrar sentido, num momento de confusas transformações. A convergência é, nesse sentido, um conceito antigo assumindo novos significados. [...] (JENKINS, 2009, p. 32).

Martino, em seu compêndio A Teoria das Mídias Digitais, assim complementa o pensamento de Jenkins elencando que a "convergência não significa que um meio novo destrua ou invalide um meio antigo [...] ambos se modificam mutuamente em uma interseção da qual emergem novos significados". (MARTINO, 2014, p. 36). O fenômeno não é, de fato, de tão simples entendimento e delimitação - até porque a própria noção de "cultura" se apresenta, de per si, bastante ampla. Para Jenkins (2009, p. 29), que analisa o termo sob o enfoque da comunicação, a convergência é um ponto "onde as velhas e novas mídias colidem, onde mídia corporativa e mídia alternativa se cruzam, onde o poder do produtor de mídia e o poder do consumidor interagem de maneiras imprevisíveis". E, embora esteja sendo moldada hoje, a convergência seria um fenômeno a se efetivar no futuro (Ibid., p. 343), com implicações inclusive na forma como participamos do processo político.

A convergência de que trata Jenkins está longe de se resumir, pois, à dimensão tecnológica que se costuma atribuir ao termo: seria apenas um dos aspectos da convergência, relevante, mas não exclusivo nem central. Nesta dimensão tecnológica, consistiria simples- 
mente no fluxo de informações entre vários suportes midiáticos, que manteriam as suas especificidades.

$\mathrm{Na}$ dita cultura da convergência ou convergência cultural é a dimensão cultural que, de fato, define o termo. Este é nosso entendimento; não se trata de mera confluência entre plataformas e conteúdos, embora o fenômeno possa abranger esse movimento, mas de mudança profunda em práticas discursivas, ou seja, no modo como se produzem e coproduzem, se distribuem e se reproduzem, se recepcionam e se reconstroem os significados construídos por diferentes recursos semióticos. Até certo ponto, as palavras de Martino robustecem a compreensão da convergência como um processo cultural mais amplo, não restrito à mídia e à tecnologia, uma vez que

a convergência é um processo cultural que acontece na mente dos indivíduos na medida em que podem ser estabelecidas conexões entre os elementos da cultura da mídia, isto é, das mensagens que circulam nos meios de comunicação, e a realidade cotidiana. [...] (MARTINO, 2014, p. 35).

Desse modo, interessa-nos colocar sob perspectiva as acepções de convergência cultural propostas por Martino e inspiradas em Jenkins. Restringir esse "processo cultural" a algo que "acontece na mente do indivíduo" seria um tanto reducionista, e um tanto destoante da linha de análise crítica de discurso que desenvolvemos, a par da perspectiva da semiótica social, cujos preceitos nos impingem a tratar a linguagem com uma abordagem não meramente formalista ou interna, mas essencialmente funcional ou externa (cf. SCHINFFRIN, 1994). Desses autores, interessam-nos as reflexões ligadas às práticas sociais, discursivas e textuais (FAIRCLOUGH, 2001, p. 101) no contexto da Era do Argumento Visual. A cultura da convergência é, em essência, fenômeno/processo cultural, da qual faz parte a "cultura da mídia". Para a ADC, é na instância da interação social que se consubstancia a cultura da convergência, ou seja, no âmbito discursivo da prática social, que se transforma substancialmente (JENKINS, 2009, p. 50).

Pode-se dizer, em epítome, que a cultura da convergência abarca questões socioculturais (individuais e coletivas), tecnológicas (meios) e semiolinguísticas (códigos, linguagens), conforme nos indica o próprio Martino (2014). Por certo, uma acepção única não seria capaz de abarcar todas as dimensões do termo. Não despreza- 
mos a dimensão tecnológica e sociocultural do fenômeno. Na seção seguinte, apontamos para alterações nos processos comunicacionais no âmbito da Câmara dos Deputados, que entendemos como mudanças não restritas à integração de plataformas e conteúdos, abarcando questões socioculturais mais amplas, estruturais, que acabam por alterar a prática discursiva institucional. No âmbito das práticas textuais, focamos questões de cunho semiolinguístico. A perquirição das alterações semiolinguísticas, como uma evolução da linguagem da mídia impressa, concretiza-se na análise do objeto empírico da pesquisa, capas da mídia impressa, o Jornal da Câmara, exame que a que se procede na seção subsequente à próxima.

\section{A cultura da convergência na Câmara dos Deputados: mudanças nas práticas discursivas no Parlamento}

Do fenômeno inescapável da cultura da convergência, que se relaciona substancialmente aos processos comunicacionais, mas também aos seus meios, não se pode furtar nenhum dos órgãos de comunicação da sociedade contemporânea, sob pena de terem suas próprias existências comprometidas. No Parlamento brasileiro, em particular na Câmara dos Deputados, a chamada cultura da convergência vem provocando reconfiguração profunda das dinâmicas de produção, circulação e consumo não somente dos conteúdos relativos à difusão da atividade legislativa e assuntos de interesse da sociedade em geral, mas também da forma como se concretizam tais práticas discursivas. Em 2011, a Secretaria de Comunicação Social da Câmara dos Deputados (Secom) propôs a convergência das mídias da instituição. Todo o processo encontra-se detalhadamente registrado na publicação Convergência e integração na comunicação pública (BRASIL, 2013). Como efeito da convergência e integração das mídias, a Secom passou a contar com apenas dois departamentos centrais: o de Mídias Integradas; e o de Relações Públicas e Divulgação. Ademais, todos os veículos de comunicação da Câmara (TV Câmara, Rádio Câmara, Jornal da Câmara e Agência Câmara Notícias) passaram a ser abastecidos por serviço único de pauta, de produção e de reportagem.

Consoante a publicação Convergência e integração na comunicação pública, em 2002, nos dias de pico de atividade legislativa, somente 
$26 \%$ das atividades, em média, eram cobertas pela Secom. Dez anos depois, em 2012, com um crescimento exponencial, em pleno processo de interseção das mídias, os números mostravam outra realidade:

A Rádio Câmara veiculou mais de 3.500 matérias jornalísticas [...]. A Agência Câmara Notícias recebeu mais de 4 milhões de visitas em 2012 e publicou cerca de 15 mil notícias. A TV Câmara Digital fechou o ano [...] com mais 36 milhões de brasileiros [...] em que o sinal de TV aberto e gratuito está disponível para a população. (BRASIL, 2013, p. 22).

O quadro a seguir ${ }^{1}$ mostra, de forma resumida, a partir da data de criação de cada veículo de comunicação, a evolução do sistema de comunicação da Câmara dos Deputados até os dias atuais.

\begin{tabular}{|c|c|c|c|}
\hline \multicolumn{4}{|c|}{$\begin{array}{l}\text { Quadro } 1 \text { - Evolução do Sistema de Comunicação da } \\
\text { Câmara dos Deputados, dos Anos } 60 \text { a } 2013\end{array}$} \\
\hline $\begin{array}{l}\text { Data de criação } \\
\text { do veículo }\end{array}$ & $\begin{array}{l}\text { Formato do } \\
\text { Veículo }\end{array}$ & Título & Órgão Editor \\
\hline $\begin{array}{l}\text { Final dos anos } \\
\qquad 60\end{array}$ & $\begin{array}{c}\text { boletim } \\
\text { informativo } \\
\text { impresso }\end{array}$ & $\begin{array}{l}\text { Câmara é } \\
\text { Notícia }\end{array}$ & $\begin{array}{l}\text { Câmara dos } \\
\text { Deputados }\end{array}$ \\
\hline 1963 & rádio & Voz do Brasil & $\begin{array}{c}\text { Câmara dos } \\
\text { Deputados e outros } \\
\text { órgãos dos Poderes } \\
\text { da República }\end{array}$ \\
\hline Década de 70 & $\begin{array}{l}\text { boletim } \\
\text { informativo } \\
\text { impresso }\end{array}$ & Informação & $\begin{array}{l}\text { Câmara dos } \\
\text { Deputados }\end{array}$ \\
\hline Década de 80 & $\begin{array}{c}\text { boletim } \\
\text { informativo } \\
\text { impresso }\end{array}$ & Câmara Informa & $\begin{array}{l}\text { Câmara dos } \\
\text { Deputados }\end{array}$ \\
\hline
\end{tabular}

\footnotetext{
${ }^{1}$ Os quadros 1 e 2 deste artigo foram elaborados pelas Articulistas, com base em dados obtidos na publicação Convergência e Integração na Comunicação Pública (BRASIL, 2013).
} 


\begin{tabular}{|c|c|c|c|}
\hline $\begin{array}{c}\text { 1987-1988 } \\
\text { (Assembleia } \\
\text { Nacional } \\
\text { Constituinte) }\end{array}$ & jornal impresso & $\begin{array}{c}\text { Jornal da } \\
\text { Constituinte }\end{array}$ & $\begin{array}{c}\text { Câmara dos } \\
\text { Deputados e Senado } \\
\text { Federal }\end{array}$ \\
\hline 1990-1998 & jornal impresso & Hoje na Câmara & $\begin{array}{l}\text { Câmara dos } \\
\text { Deputados }\end{array}$ \\
\hline 1998 & jornal impresso & $\begin{array}{l}\text { Jornal da } \\
\text { Câmara }\end{array}$ & $\begin{array}{l}\text { Câmara dos } \\
\text { Deputados }\end{array}$ \\
\hline 1998 & TV & TV Câmara & $\begin{array}{l}\text { Câmara dos } \\
\text { Deputados }\end{array}$ \\
\hline 1998 & rádio & Rádio Câmara & $\begin{array}{l}\text { Câmara dos } \\
\text { Deputados }\end{array}$ \\
\hline 2000 & site & $\begin{array}{c}\text { Agência Câmara } \\
\text { de Notícias }\end{array}$ & $\begin{array}{l}\text { Câmara dos } \\
\text { Deputados }\end{array}$ \\
\hline
\end{tabular}

A TV Câmara resulta da Lei no 8.977, de 6 de janeiro de 1995, a Lei do Cabo, que previu a inclusão de canais de acesso público e estabeleceu reserva de canais de TV a cabo para informações de interesse público, como os comunitários, universitários e legislativos. Em 1998, as mídias radiofônicas e televisivas passaram a fazer parte do sistema de comunicação da Casa Legislativa, cada vez mais abrangente e poderoso. Finalmente, a página virtual, a Agência Câmara de Notícias, que, além dos conteúdos próprios, congrega todas as outras mídias, começou suas atividades em 2000, ou seja, há menos de quinze anos. Assim, no ano de 2014, a par dos três principais canais de comunicação (site, TV e rádio), ainda se publica e distribui o Jornal da Câmara, jornal composto de oito páginas impressas, reproduzidas na página virtual da Casa.

Vale assinalar que, em 18 de março de 2015, pela primeira vez na história da Casa, designa-se um deputado, e não um servidor concursado, como Secretário de Comunicação, em face do poder crescente da mídia parlamentar, que parece tornar-se cada vez mais político-partidária, em detrimento de sua intrínseca característica institucional. 


\section{Do logocentrismo à multimodalidade: alguns efeitos da cultura da convergência na linguagem da mídia institucional}

Nesta seção, buscamos relacionar o emprego de uma linguagem cada vez menos monomodal (modo escrito) nos jornais impressos, como um dos efeitos da cultura da convergência, que faz aproximarem as linguagens empregadas nas mídias antigas e novas. Conforme argumentamos, a cultura da convergência está afeita a questões de cunho semiolinguístico. Buscamos, no âmbito das práticas textuais, traços dessas mudanças na ordem do discurso contemporânea, em que ganha espaço o modo visual em textos multimodais. O corpus de análise textual/composicional constitui-se de mídia da Câmara dos Deputados em que os modos escrito e imagético disputam lugar: o jornal impresso. Trata-se de texto multimodal, cujos significados se realizam por mais de um código semiótico (KRESS; VAN LEEUWEN, 2006).

O jornal impresso da Câmara, desde 1960, vem sendo repaginado e reintitulado. Passou a chamar-se Jornal da Câmara em 1998. Em 2011, incluiu conteúdos institucionais, além dos tradicionais conteúdos legislativos. A expansão do conteúdo - da cobertura de atos legislativos à divulgação também de atos e fatos institucionais - atrela-se à meta de fortalecimento institucional, ao objetivo de aperfeiçoar e massificar a comunicação com a sociedade civil organizada e a imprensa, e à estratégia de intensificar a comunicação dos resultados positivos da Casa, por meio de "informações em linguagem adequada, de forma isenta, apartidária e confiável” (BRASIL, 2013).

Para vislumbrar a evolução da linguagem no jornal impresso, especialmente em relação ao emprego de recursos semióticos do modo imagético - eis o nosso foco de análise -, cotejamos capas de seis edições do Jornal da Câmara, entre 1999 a 2014. O principal critério de escolha, a par do temporal, já explicitado, foi a predominância dos modos semióticos escrito e/ou imagético. Propositadamente, trasladamos as imagens em tamanho suficiente para certa macrovisão da distribuição espacial dos recursos semióticos empregados nos cluster, desprezando, porque não nos interessa a este estudo, eventual análise léxico-gramatical de sentenças.

A análise dos significados verbais busca tomar o texto escrito como um todo ortográfico, componente do cluster. Procede-se tão só ao descortino da interação semiótica por meio da análise dos princí- 
pios de estruturação, como valor da informação, saliência e moldura. O cluster define região específica ou sub-região da página como um todo, por exemplo, o espaço destinado à manchete em jornal impresso, ou a legenda de foto, ou a uma ilustração. Consiste em conjunto local de itens em webpage ou página impressa (BALDRY; THIBAULT, 2006, p. 31). É a proximidade espacial que permite a identificação de clusters, que podem realizar-se nos modos escrito, verbal, imagético, audiovisual, integrados ou não, no interior do cluster. Eis o nosso corpus de análise:

Capas do Jornal da Câmara - entre os anos de 1999 e 2014

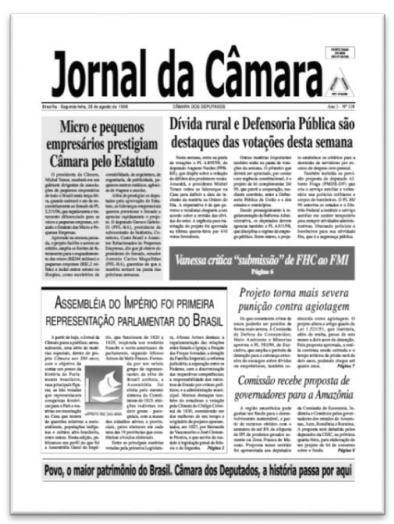

Figura 1: Capa da edição de 23 de agosto de 1999

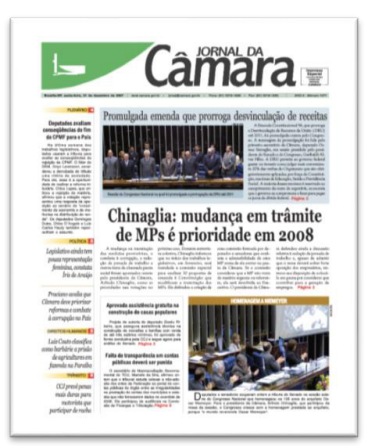

Figura 4: Capa da edição de 21 de dezembro de 2007.
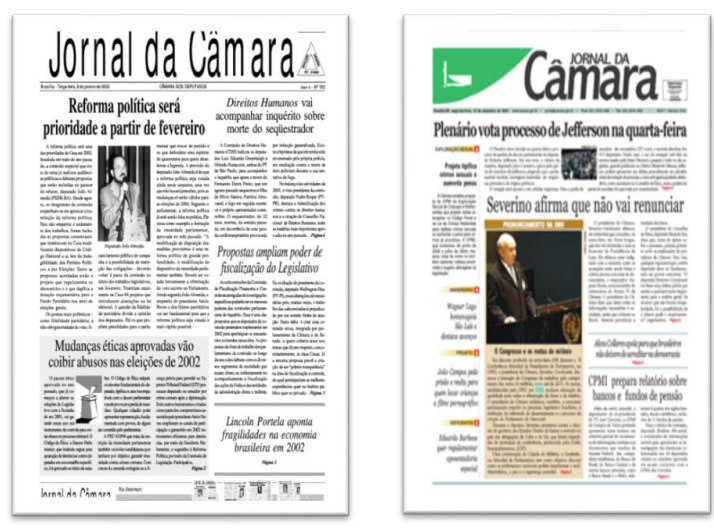

Figura 2: Capa da edição de 8 de janeiro de 2002 .

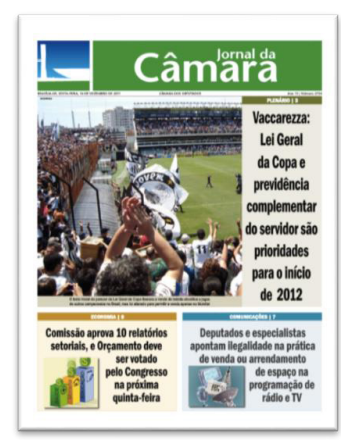

Figura 5: Capa da Edição de 16 de dezembro de 2011.
Figura 3: Capa da edição de 12 de setembro de 2005.

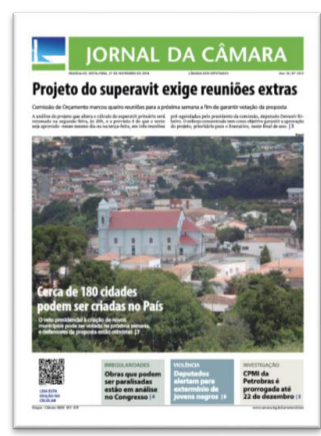

Figura 6: Capa da edição de 21 de novembro de 2014. 
A composição espacial do significado envolve sistemas relativos ao valor da informação, à saliência ou projeção dos elementos (participantes e sintagmas representacionais) e ao enquadramento ou framing (KRESS; VAN LEEWEN, 2006). Note-se que a organização geral dos textos acima reproduzidos apresentam elementos invariáveis, como a distribuição espacial dos clusters na página e enquadramentos. Tal lógica organizacional do layout provém de práticas sociais ligadas a estruturas e instituições sociais mais antigas e perenes (ordens do discurso), características do gênero jornalístico e da mídia impressa. Nestes, compósitos como título do jornal, manchetes, textos escritos e imagens visuais integram-se para a construção do significado semiótico (em ancoragem ou revezamento), impressos com tinta e suportados por páginas de papel, em frente e verso. Estes são, pois, elementos fixos, invariáveis, previsíveis. Foquemos, pois, os elementos que se diferem nas capas, mudanças na concretização textual, como efeitos discursivos da cultura da convergência.

Já num primeiro olhar, é possível notar o acréscimo de cores à impressão do jornal, na capa de 2005 (Fig. 3). As cores das fotos e ilustrações, assim também na logomarca, aumentam o contraste, antes realizados apenas com tons de preto e cinza. Revela-se, entre outros fatores, maior preocupação em atrair a atenção do leitor (Ibid., p. 183), por meio da saliência dos recursos semióticos. A análise das cores está inserta na categoria de saliência ou projeção e diz respeito ao grau em que um elemento propicia atenção a si mesmo e como o faz. A primeira edição colorida do jornal data de 11 de junho de 2003 e mostra maior denodo na composição do layout da página, inclusive nas formas e cores da logomarca do jornal e da instituição.

Para a análise composicional das capas, a categoria chamada projeção ou saliência leva em conta a localização em primeiro ou segundo plano, as diferenças de nitidez e o tamanho relativo dos elementos. Quanto a este critério, nota-se que, passados os anos, tornam-se maiores e espacialmente prevalentes os clusters que têm imagens como modo semiótico predominante. Distingue-se nitidamente o aumento percentual gradativo dos recursos semióticos do modo visual, em comparação à ocorrência do modo escrito. Para Kress e van Leeuwen (2006, p. 212), intuitivamente os leitores têm a capacidade de fazer julgamento acerca da relevância dada a cada elemento da composição, de acordo com o destaque imprimido pelo produtor do signo (sing-maker). 
Para se construir a coerência da composição, necessário distinguir os caminhos potenciais de leitura. Ao compulsar as capas trasladadas, percebe-se que a trajetória de leitura modifica-se substancialmente (KRESS; VAN LEEWEN, 2006), reiterando o valor ou peso dos cluster na composição do significado, já marcados pelas cores, pelo tamanho e pelo lugar que ocupam nas páginas.

Nas duas primeiras edições (Fig. 1 e 2), a leitura das páginas prevalentemente monomodais ${ }^{2}$ se dá a partir da manchete do jornal. A trajetória de leitura ocorre da esquerda para a direita e de cima para baixo (leitura da escrita ocidental). Esta trajetória de leitura é tratada por Silva (1985), em sua obra Diagramação: o planejamento visual gráfico na comunicação impressa, como um caminho que se percorre pelas zonas de visualização; equivaleria à trajetória que iria da zona primária (superior esquerda) à zona secundária (inferior direita).

Na terceira edição (Fig. 3), a foto colorida do Deputado ao centro (no nível do olhar do viewer/leitor) posiciona-se como núcleo da informação visual. Em segundo lugar, a atenção tende a voltar-se à manchete escrita acima da imagem, que integra o sentido da imagem. Em seguida, dirige-se o olhar para o cluster onde se encontra a manchete escrita, no topo da página. Assim, a trajetória vai do centro ao topo e, em seguida, para as margens.

A quarta edição (Fig. 4), de 2007, mostra uma evolução considerável no layout. Da manchete, escrita ao centro, parte o vetor, que tende a seguir para a imagem superior esquerda e, em seguida, a inferior direita. Vale lembrar que, naquele ano, a Apple lançou a primeira geração do revolucionário I-Phone, que alterou as convenções até então reinantes na telefonia móvel. Com tela sensível ao toque, combinaram-se, num gadget compacto, as funções de telefone, navegador de Internet e player de mídia. Na quinta capa (Fig. 5), o vetor parte da imagem à esquerda, em saliência, e segue em direção ao texto escrito enquadrado à direita. Somente depois parte para a leitura dos clusters multimodais (escrita e ilustração) abaixo à esquerda e à direita.

Finalmente, na última capa (Fig. 6), a imagem ao centro atrai o olhar do viewer/leitor para a igreja central e compõe processo narrativo intransitivo (elucidamos abaixo). Da imagem, o vetor se dirige ao texto que se lhe sobrepõe (e lhe integra a construção do sentido), seguindo para a manchete ao topo e, finalmente, aos clusters abaixo.

${ }^{2}$ Pelo princípio da Teoria Semiótica Social da Multimodalidade, todos os textos são multimodais. As capas dos dois primeiros jornais, em preto e branco, têm textos escritos contrastados em cor cinza, negritados, enquadrados, topicalizados ou marginalizados, etc. 
Note-se que, nos primeiros quatro exemplares, as fotos retratam o ambiente interno da Câmara, e de fato prevaleceu nos clusters imagéticos, por muitos anos, exclusivamente fotos de Parlamentares em close nas tribunas do plenário, geralmente em frente ao microfone com a boca aberta, flagrados em plena atividade elocutória. Kress e van Leewen (2006, p. 61) chamam este participante representado de ator, em estrutura não transitiva, ou seja, cujo vetor não se dirige a um "objeto" (pessoa, lugar ou coisa). A intransitividade revela-se na ausência do objeto "receptor" ou "leitor", ou do vetor ator P participante ativo. Além das fotos em close, eram comuns em edições anteriores fotos de Parlamentares reunidos nas Comissões Temáticas e gabinetes. Assim, os leitores do jornal, Deputados ou não, poderiam sentir-se envolvidos nas ações representadas (VAN LEEUWEN, 1996).

À medida que o jornal aumenta a sua tiragem e passa a tratar de assuntos não só legislativos mas também institucionais (além do âmbito interna corporis), passa a haver preocupação com o viewer cidadão. As imagens de ambientes e de pessoas "externas" ao Parlamento começam a ocupar lugares maiores e mais privilegiados no clusters (menos marginais, mais centrais), com a prevalência de processos transitivos em composições narrativas.

Nos enquadramentos, observa-se a separação espacial dos clusters escritos e imagéticos, que se relacionam, mas não se sobrepõem. Na última capa (Fig. 6), contudo, vê-se texto escrito sobreposto à foto que, centralizada, ocupa quase a totalidade da página. Reconhece-se a integração completa dos recursos semióticos, tendência absoluta na produção do sentido das novas mídias, ante o fenômeno da cultura da convergência. Texto e imagem constroem, de forma complementar, o significado linguístico da composição. Trata-se do princípio da integração dos recursos semióticos, o "coração da multimodalidade" (BALDRY; THIBAULT, 2006, p. 4): todos os recursos semióticos tipicamente se combinam para realizar a produção de sentido.

Sobre os significados construídos por arranjos visuais, Silva elabora interessante noção de discurso gráfico, ao considerar que

o arranjo gráfico passa a atuar como discurso; e como discurso, possui uma linguagem específica e uma rede encadeada de significação. É preciso que os planejadores gráficos tenham consciência da importância dessa linguagem e o seu poder de manipulação." [...] (SILVA, 1985, p. 60). 
A análise multimodal do corpus, por certo, não se esgota nestas parciais considerações, mas estas são suficientemente extensas para aquilo a que fundamentalmente se propõe o artigo: entender como o contexto da cultura da convergência vem se consubstanciando nas práticas discursivas e nos textos midiáticos públicos, inclusive naqueles produzidos pela Câmara dos Deputados do Brasil.

\section{Considerações finais}

Como demostrado pelo trajeto da análise na presente pesquisa, a cultura da convergência como nova prática social significa um marco na Era do Argumento Visual, recrudescida com a expansão da World Wide Web no início dos anos 2000 e a dinâmica Web 2.0. Os efeitos se fazem sentir em grande parte dos gêneros discursivos, que se relacionam às novas práticas sociais e até então inéditas formas de agir (FAIRCLOUGH, 2003). Jenkins (2009, p. 30) fala da produção coletiva de significados e de como esta, na cultura popular, "está começando a mudar o funcionamento das religiões, da educação, do direito, da política, da publicidade e mesmo do setor militar".

Logo, parte irredutível da vida social (FAIRCLOUGH, 2003), a linguagem conecta-se aos elementos sociais, eventos e práticas, e o faz de forma dialética, modificando-os e sendo por estes modificada. A descentralização ou deslocamento da linguagem verbal escrita do centro da interação comunicativa é importante indício de que a cultura da convergência vem modificando a ordem do discurso midiático. O gênero jornalístico testemunha a aproximação, a convergência e a integração da linguagem das mídias analógicas e digitais, das antigas e das novas, o que se dá de forma avassaladora, vasta, profunda e definitiva. Martino (2014, p. 38) aduz que, na cultura de convergência, "não só as divisões entre formas de produção e recepção da cultura mudam, mas a própria maneira de contar histórias encontra outros caminhos".

Desse modo, a visibilidade da mudança nas práticas discursivas, que se nos parecem neste estudo tão escancaradas e registradas, faznos perceber que o fenômeno da convergência cultural está ainda para ser desnudado, em seus atuais e vindouros efeitos sociais e discursivos. 


\section{REFERÊNCIAS}

BRASIL. Câmara dos Deputados. Secretaria de Comunicação Social.

Convergência e integração na comunicação pública. (Org.) Evelin Maciel. Brasília: Câmara dos Deputados, Edições Câmara, 2013, 158 p. Série gestão institucional/Relatórios, n. 3 .

BRASIL. Congresso Nacional. Anais da Câmara dos Deputados. Rio de Janeiro: Imprensa Nacional, 1951, p. 8.273-8.274.

BALDRY, A.; THIBAULT, P. J. Multimodal transcription and text analysis: a multimedia toolkit and coursebook. London: Equinox, 2006.

CASTELLS, Manuel. A sociedade em rede. São Paulo: Paz e Terra, 1999.

FAIRCLOUGH, Norman. Discurso e Mudança Social. (Coord. Trad.) Izabel Magalhães. Brasília: Editora Universidade de Brasília, 2001.

Analysing discourse: Textual analysis for social research. London: Routledge, 2003.

HABERMAS. Jünger. Mudança estrutural da Esfera Pública. Rio de Janeiro: Tempo Brasileiro, 1984.

JENKINS, Henry. Cultura da Convergência. Tradução de Susana Alexandria. 2. ed. Rio de Janeiro: Aleph, 2009.

KRESS, G. VAN LEEUWEN, T. Multimodal Discourse: The modes and media of contemporary communication. London: Arnold, 2001.

. Reading images: the grammar of visual design. 2. ed. London, New York: Routledge, 2006.

MARTINO, Luís Mauro Sá. Teoria das Mídias Digitais: linguagens, ambientes e redes. Petrópolis, RJ: Vozes, 2014.

SCHIFFRIN, D. Approaches to discourse. Oxford: Blackwell, 1994. 
SILVA, Rafael Souza. Diagramação: o planejamento visual gráfico na comunicação impressa. 2. ed. São Paulo: Summus, 1985.

VAN LEEUWEN, T. The representation of social actor. In: CALDAS COULTHARD, C.R.; COULTHARD, M. (Eds.). Texts and practices: reading in Critical Discourse Analysis. London: Routledge, 1996. 
AÇÃO MIDIÁTICA, n.11. Jan/jun. 2016. Curitiba. PPGCOM-UFPR. ISSN 2238-0701

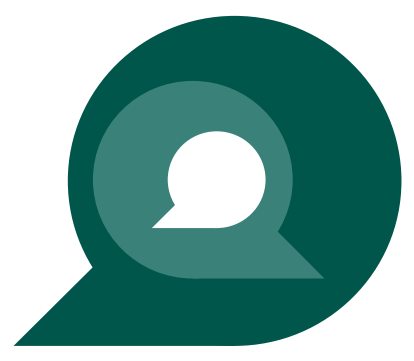

